\title{
Communication-based Auto-control in Construction and Repair Activities
}

\author{
PhD Student Radostina Petrova \\ University of Economics - Varna, Varna, Bulgaria \\ radostina_petrova@ue-varna.bg
}

\begin{abstract}
Inefficient control is problematic in all business sectors notably in the manufacture. Accumulation of unresolved problems in some industries like construction befalls tangible losses like financial, material, human, etc. That causes a subsequent negative effect not only on contractors but also on clients and end-users. There is not a universal solution for quality control, applicable in all projects and processes. Therefore, it is a present-day case study to explore the main issues in various management control systems (MCS). The article emphasizes the necessity of an automatic controlling tool for monitoring and tracking performance in all phases of a construction project. Using qualitative and quantitative research methods as well as statistical methods of analysis, we examine whether communication plays a key role in the controlling process. Thereafter, we prototype a new communication-based mobile application, which allows controlling construction and repair activities automatically.
\end{abstract}

Keywords: Information Technologies, Management, Communication, Construction, Control

JEL Code: L740; doi:10.36997/IJUSV-ESS/2019.8.2.110

\section{Introduction}

Construction contributes to employment rising. It creates both full-time and part-time or seasonal jobs. The sector drives economic growth and provides solutions for social, climate and energy challenges (European Commission, 2019). It builds facilities for the future which the population relies on. Residential, business and transport infrastructure like assets, buildings, factories, power electrical stations, highways, etc. are only a small part of the end product. Therefore, the qualitative control is at the core of the construction industry. Every process, part of construction projects (ex. task completion, used materials and equipment), should rely on a versatile manner for quality examination. Otherwise, the end product/service leads to irreversible consequences - material, financial, and in the worst case, human losses.

Communication and control are essential to any business activity. Their deficiency is a prerequisite for dissonance between plans and results. Stages/Phases in the construction sector are interdependent. Each new stage/phase begins where the previous one ends. Errors, made in one of the phases, could countermine a whole project. Therefore, it is useful to investigate the most common barriers in controlling and available IT solutions for their overcoming.

We assert that a mobile web application for communication has the potential to embody automatic control in each phase of the construction project.

The purpose of the report is to design a mobile application for tracking the frequency of communication. Data collection and their reliable interpretation drive algorithms to analyze particular parameters, specified in advanced by managers or gathered automatically via technology for caching traffic. The last one derives from the text, video, audio calls, and messages. Thereby, our idea can be upgraded to some form of artificial narrow/ general or superintelligence. The tasks we follow are:

1. To specify the phases of the construction activities;

2. To identify the most common practices for construction controlling;

3. To review the advantages and disadvantages of the currently used communication tools between stakeholders;

4. To clarify the causal connection between errors and risks;

5. To design a communication-based auto controlling tool.

\section{Common Practices in Construction Management}

Activities in construction require working with a project team. Teams for small projects are 
easier for coordinating rather than those for bigger ones. More construction projects engage multiple teams (for example design, construction teams, etc.), qualified in different activities. Although the management is a challenge, job and professional interests unite employees.

Team management is a work of art. It depends on the project manager's skills. Some of the key factors he/she has to possess are team building, motivating teams, conflict management, developing consensus, team conduct. The project and teams' success also pivots around efficient communication. Conversation, however, is bound to subjective interpersonal skills, rather than objective ones. Communication in construction does not have to depend on the human individuality because the flow of information between workers, managers, stakeholders about the nature of projects is endless. At the same time, the knowledge about work assigning, teams' engagement, task completion, etc. has to reach many participants. Unfortunately, the available tools seem to be incomplete, inefficient and unreliable. The statement is also confirmed by Paul Marsden (2019), who writes in his career in construction he is trained to use the same quality control tools like the ones in the 1960s (Marsden, 2019, p. x).

Oberlender (2001) describes the mastery of construction management as a ladder of thirteen steps:

1) working with project teams;

2) project initiation;

3) early estimates;

4) project budgeting;

5) development of work plan;

6) design proposals;

7) project scheduling;

8) tracking work;

9) design coordination;

10) construction phase;

11) a project closeout;

12) personal management skills;

13) quality skills (Oberlender, 2001).

The thirteenth step underlines the need for a backward connection. Even if the project has been finished, the exploited site needs observation. Some objective measures on customers' satisfaction would help construction companies achieve continual improvement. It concerns both employees and company results, including management commitment, training, teamwork, statistical methods, cost of quality, supplier involvement, customer service, implementation. Many authors and constructors argue that in construction a big part of the information is lost or it is unable to be provided to another team (Xu \& Luo, 2014, p. 8).

The primordial constructive teams have all the experience and information but, usually, they are not engaged with the maintenance during exploitation because they are involved in other projects. Therefore, it is not easy for other teams to continue, to repair or to repeat the initial idea and performance. A centralized mobile application would help no information to be lost because it facilitates the procedures for transmission of data.

Traditional construction documentation is enormous and it takes too much time to read it. Sometimes, the last one appears to be virtually impossible. Thereupon, a computer-based application with reliable functions for speed search is a relevant solution.

Team management, undoubtedly, has a significant role. For its better regulation, construction projects are divided into the following phases: conception, design, pre-construction, procurement, construction and post-construction (Gilliland Construction Management, 2019) \& (Iris Construction, 2019). A good integration has to be ensured between the enlisted phases.

Customers initialize the conception phase. Its duration depends on clients' preferences like their initial ideas, deadlines they set, the project complexity.

In general, constructive agents gather the client's desires. The project manager or management 
team sort them, create a concept and take it to the second phase. Although it is called the design phase, it refers to the timeframe of the bidding process. It is part of the preliminary design. International Association of Dredging Companies (IADC) describes that a detailed design for all competing projects has to be prepared. The phase presumes that all feasible alternatives have been considered, and a single project has been identified which meets the established economic, financial and environmental criteria (IADC, 2019). The preliminary design is then developed into a detailed engineering design package. It is the engine for developing a set of specifications suitable for soliciting tenders from contractors. Furthermore, at the end of the detailed design, the client should have a reliable cost estimate upon which to base an evaluation of submitted tenders (IADC, 2019). The detailed design process has some very important elements. Iris Construction (2019) notices that different contractors or construction companies (depending on the size of the project) bid on the job based upon the overall design and their ability to complete it within the set period. The client and project manager determine the size, and overall look, while they also research what sort of equipment is necessary to get the job done (Iris Construction, 2019). After the design contracts are drawn up and one is selected to complete the work, the next step is pre-construction.

In the third phase (pre-construction) a project team is prepared. It includes engineers, a project manager, and other applicable positions that are required to oversee and complete the project (Iris Construction, 2019). Oberlender (2001) emphasizes a team can be small and derived from a company, but sometimes it could cover multiple participants from different businesses (Oberlender, 2001). According to the legal regulation, each start of construction requires pre-testings. The chosen land to build is checked, soil testing and a site examination are made to ensure there will not be any environmental damage as a result. After thorough research is completed, the proper authorities review and approve (Iris Construction, 2019). Hereupon, the procurement phase starts. It encompasses obtaining all of the proper equipment, materials, laborers and likely even subcontractors. Each job is different, so the general contractor has the opportunity to do most of this work by itself or delegate it to subcontractors (Iris Construction, 2019).

Much of the work has to be done before the construction phase begins. Phase consistency is also important so that when it comes time to break ground, everyone can come together and be at the same level. Everyone is given a schedule, from laborers' hours to job-site accessibility. If no major concerns, the project is completed and the construction phase meets the deadline (Iris Construction, 2019).

Authors like Klinger \& Susong (2006, p. 175) report about the common misconception that once the building or project is completed and built, that means the whole work is done. The final postconstruction phase is very important before and after the site is put into final exploitation. A thorough inspection and cleaning are done to ensure it is safe and completed as discussed, and it is important that all users feel safe and understand how everything can be utilized. It is essential that this final step is completed appropriately and nothing is left pending for anyone involved (Iris Construction, 2019). The post-construction phase needs customers' feedback. That makes the phase an endless sequence of processes, grouped for the purposes of the total quality management. Construction companies should care about customers' satisfaction, new ideas for continual improvement, statistics, cost of quality, etc. and do their best to maintain their brand, image, reliability and consumers' confidence (Oberlender, 2001). Good software establishes a connection between constructors, customers, and end-users, even after the project completion.

The aforementioned phases show all steps in construction are interconnected and quality control is essential for the success of projects.

\section{Advantages and Disadvantages of Quality Control Procedures in the Construction Sector}

Teams, working on a project, use systems (tools, equipment, processes, procedures) to complete the work. Peter Furst (2012) points three basic elements that require execution and control. 
They are:

1. product/project - the building;

2. process - the tools, technology, management systems, etc.;

3. people - the project team (Furst, 2012).

Quality control (QC) procedures are a code of guidelines. Traditionally, they are written documents, which set and establish the quality standards and norms which ensure products and service comply with requirements (Swamy, 2019). Some standards can be unclear and that leaves too much room for wrong interpretation. Companies have to create systematic and uniform approaches to getting work done. The paradox is some QC tools are 'not as effective as they could be in identifying defects early in the construction process' (Akinci, et al., 2006).

The mechanisms for creating and keeping quality control procedures are quality policy and procedure documents. They contain information and guidelines as to how total quality management should be maintained. Some of the most common procedures for quality control are:

1. physical quality guidelines;

2. inspections, approvals, and certifications;

3. inspection and test plans and certificates;

4. methods and sequence of tests;

5. acceptance and rejection criteria;

6. key control points;

7. performance specifications;

8. visual quality (Sitemate, 2019).

Marsden (2019, p. x) considers inspections, test plans, and quality management systems are still based on the quality standards introduced in the 1980s, such as ISO 9001, with project quality plans and internal audits, albeit with a new emphasis on risk management (Marsden, 2019, p. x).

Innumerable authors write construction slowly adopts new ICT; however, in our opinion, the problem is not that there is a lack of computer systems and technologies, applicable in the construction sector. There is pretty much software for different constructive and reconstructive activities. Some of the examples of computer-based construction management systems with quality control we can give are FINALCAD, Build7, Procore, PlanGrid, Bridgit Field, RedTeam, Buildup, Fieldwire, PMVitals, Nexvia, BIM 360, Dashpivot, BuildSafe, Onware, Fieldlens, Manage-IT by Atser (GetApp, 2019). It is hard to say which one is the best because it depends on company needs. Our research, however, shows the products are expensive and companies rarely invest in IT services. That can be confirmed with several statistical facts. According to JBKnowledge (2018), 54\% of construction companies have R\&D departments for new technology, but only $16 \%$ of them have more than 5 employees there. Comparing to 2016, when the portion of companies, which experiment with drones is $27 \%$, in 2018 it has increased to $37 \%$. More than half of construction companies are considering job-site employee tracking $(57 \%)$. Just $11 \%$ of general contractors are using wearable technology. Only $24 \%$ of construction employees are "very comfortable" with new technology. 39\% of companies cite "lack of IT staff" as the most limiting factor in adopting new technology ( (JBKnowledge, 2018) and (Imbimbo, 2018)). In 2018 there was a 12\% growth in the number of construction firms using Building Information Modeling (BIM) software (NBS, 2018, p. 19).

A successful project has to meet the contract terms and the expected quality level. Unfortunately, constructors repeat ineffective practices that lead to suboptimal results, such as low productivity, poor quality, worker injuries, etc. Recognizing these ineffective practices will assist in avoiding them (Furst, 2012). Peter Furst (2012) claims that project delivery risk has two elements, which have to be managed efficiently. They are risk assessments and risk control. The first one involves identification, analysis, and centres, while the second one includes planning, resolution, and monitoring. Combining estimates of loss magnitude with failure is the usual way of evaluating risk situations (Furst, 2012). The last sentence could be realized in any computer system. Otherwise, the risk level increases the possibility of incidents, injuries, and losses. Furst (2012) considers that following some common industry practices and procedures contribute to adverse project safety. Some 
of his suggestions for improvement, we display tabularly (see table 1) as currently unresolved issues.

Table 1. List of Advantages and Disadvantages of Currently Used Controlling Methods

\begin{tabular}{|c|l|l|}
\hline № & \multicolumn{1}{|c|}{ Advantages } & \multicolumn{1}{c|}{ Disadvantages } \\
\hline 1. & Based on clear written rules & Too much documentation is hard for analysis \\
\hline 2. & Inspection by qualified experts & Subjectivism and conflict of interest \\
\hline 3. & $\begin{array}{l}\text { There are standards and all projects have } \\
\text { to follow them }\end{array}$ & $\begin{array}{l}\text { Rules and standards can not cover unique } \\
\text { projects }\end{array}$ \\
\hline 4. & $\begin{array}{l}\text { Simultaneously computer-based and real } \\
\text { physical control can be made }\end{array}$ & Psychological pressure on performers \\
\hline 5. & & Unclear standards \& wrong interpretation \\
\hline 6. & & Lack of careful analysis \\
\hline 7. & & Ineffective risk assessment \\
\hline 8. & & Inferior planning \\
\hline 9. & & Poor partner selection \\
\hline 10. & & Poor preconstruction practices \\
\hline 11. & & Misaligned systems \\
\hline 12. & & Little cross-functional communication \\
\hline 13. & & Insufficient company oversight \\
\hline 14. & & Metrics \\
\hline 15. & & Conflict resolution \\
\hline 16. & & Lack of motivation \\
\hline 17. & & Employees' lack of capability \\
\hline 18. & & Heroism \\
\hline 19. & & Unrealistic expectations \\
\hline
\end{tabular}

Source: Adapted to (Furst, 2012)

Traditional QC methods have more disadvantages than advantages (Table 1). That is an indicator of ineffective communication, so new models for quality control should be used.

Building information modeling (BIM) is a digital representation of a complex construction product. It contains precise product information data but to obtain construction-oriented data and linking information that is crucial to manufacturing and quality control and assurance with still remains a challenge (Martinez, et al., 2019, p. 146). The authors propose a new model for quality control, based on BIM results. The quality control ontology links the construction quality control and assurance information from different standards (international, national, local), regulations or codes, company specifications with the manufacturing and product information (Martinez, et al., 2019, p. 146). The regulations are stored as a database and are linked to a 'Material' and/or 'Manufacturing Operation' and define the quality control that is necessary for the manufactured product. For construction manufactured products, three different areas for quality control and assurance are defined: (1) 'Material Testing' is the requirement to test the physical properties of the materials used on the product; (2) 'Element Inspection' is the inspection of the product as a whole, focusing on defects that may endanger the integrity of the product (geometry, missing elements, wrong materials, etc.); (3) 'Finishing' relates to the aesthetic inspection of the product, which is in most cases specific to the company (Martinez, et al., 2019, p. 146). The authors conclude that the method, at this stage, has a limited potential, and it should be improved.

\section{The Causal Connection Between Mistakes and Risks}

The lack of careful analysis applies to the operational plan and to the schedule. The schedule is based on assumptions of subcontractor performance, workforce productivity, and staff management or leadership capabilities. Unrealistic assumptions create situations where the work plan needs to 
quickly change to recover from unanticipated situations and thereby increase the potential for adverse outcomes. Schedules without appropriate plans, resources, and systems to adequately address the challenges also appear to be problematic because that reflects on the project staff. In some situations, the change is beyond their capability.

Some of the risks are typical, while others are specific and unique to a job. The outcomes of all incidents associated with increased risks are not fatal to the project, but they do have some adverse effects. It tends that risk assessment gets less attention due to time constraints and performance demands, resulting in the possibility of greater risk. That is why it is wiser to spend time to anticipate some of the potential disruptions and have possible recovery plans available.

Planning involves logistics-proactively addressing the impact of potential changes, drawing up recovery plans on how to best deal with them, understanding constraints, and implementing workarounds (Furst, 2012). All of these proposals require much-qualified staff, who control all project requirements are kept and everything goes according to plan.

Nacheva \& Sulova (2018) conclude that there is a need for a strategy for building a user experience (UX). Its successful implementation dependents directly on the study of the target audience of the product or service. Users' expectations and behavior change constantly. This often requires user surveys to be conducted in order to retrieve the best and most competitive ideas and plans for improvement (Nacheva \& Sulova, 2018, p. 138).

The management of some companies takes the decision to reduce the number of employees. That means the quality decreases automatically because both criteria follow a proportional dependency. Here we come across the same question - how to assure quality, even if the staff is small or unskilled. Organizing additional training, education, courses for self-improvement, motivation policies, etc. are considered to solve this problem; however, it appears that it does not work everywhere and in some cases, it leads to overindulgence.

Furst (2012) pays attention to the poor partner selection. From his point of view, contractors are only as "good" as their subcontractors are. Therefore, subcontractor selection is critical to project success. The capability of the subcontractor's project staff ensures that the subcontractor assigns competent people, otherwise, the incompatible personnel should be replaced before they create problems on the job.

Time, which is spent before construction starts, comes out more expensive than problems, occurred during construction. The first area covers the creation of the initial project schedule and operational plans, subcontractor selection, and project risk assessment but also establishing the budget, staff selection, and metrics that identify issues early on, as well as company active oversight to ensure that everything is progressing as it should and rapid and effective problem identification as well. Companies change their internal systems and revise their policies, standards, and procedures, which, in many cases, are not carefully reviewed for any potential conflict with already existing ones. These discrepancies confuse staff. Workers have to choose between conflicting directions or objectives. Another important fact due to the need for specialization is that organizations are vertically organized (Furst, 2012). Usually, a department or a division ends up with its own special practices and goals that serve to its individual needs but not to the whole organization ones. This problem can be categorized as a system-driven risk. It is difficult to be identified, assessed, and resolved in the field, especially where safe work is involved (Furst, 2012).

Specialized functions for efficiently and effectively performance are based on own unique processes and practices. Sometimes that may create barriers to cross-functional communication and flow of information, which ultimately is to the detriment of the organization. Inferior cross-functional communication impacts expedited decision-making and problem-solving. Different profit centres, business units, or project profitability goals with own management structures can be in "competition" with each other for performance results. That risk potentially increases the likelihood of losses and accidents (Furst, 2012).

It is a well-known fact that metrics drive organizational behavior. Therefore, senior management must be sure that all metrics work correctly. When people work together, there are 
differing opinions and conclusions. This points to the need for organizations to have a structured process of how to address conflict, quickly and effectively address the underlying issue, and resolve it expeditiously (Furst, 2012).

A Sulova's research (2016) shows machine learning is a good tool for intelligent analyses. The rapid development of social networking and sharing capabilities provide many of the applications running on the Internet. That is a prerequisite for the generation of large collections of consumer reviews, impressions, shared feelings, and emotions. Intelligent business analyses of these customer reviews are important to the business and therefore are subject to a research interest in recent years (Sulova, 2016, p. 464).

According to some statistics, the construction industry rarely hires women and their share is merely 9\% (Bureau of Labor Statistics of the United States, 2018). This portion can be increased by giving them the chance to contribute to the construction because they are more into details and quality assurance than men are. Disadvantaged people are also rarely employed. Therefore, our suggestion is women and disadvantaged people, as well as children, to receive the chance for contributing to the machine learning process. That would decrease the number of unemployment as it creates new workplaces.

\section{Web-Based Mobile Tool for Communication and Auto-Control}

There are many software products for planning, scheduling, designing, cost and vendor management. They are strongly reliable but paid. Some companies like Oracle, Trimble, Autodesk, etc. develop new software products for construction or buy existing ones and improve their features.

The most convenient software for construction activities is integrated. Construction companies prefer paying for receiving all IT features in one system, rather than paying for separated parts. However, the problem they face concerns the need for additional staff IT preparation. Any new or extra obligation distracts employees' time and it does not allow them being concentrated only on construction. They have to think about the IT product and how to use its full potential.

A good solution for overcoming this problem is creating both integrated and interactive online software for project management in construction. If there is a platform where teams can collaborate, follow all assigned them tasks and track progress, the construction process completion becomes faster. One online tool for construction has to be cloud-based with assigned accessing roles. It should allow simultaneously teamwork and project monitoring, as well as, dashboards with Gantt charts, team schedules, task lists, timesheets. It is useful if the tool can be installed as a mobile or desktop application for offline work. Computer products should also allow resource allocation and management, online file storage, email alerts, etc.

Some IT solutions, supplied on the market are cloud-based. They scale with the largest of projects and they control and track the progress. The most common between all IT solutions for project management is that they represent issue tracking systems. Received notices are arranged into tickets. The problem is that when too many unresolved tickets are gathered, they may stay unseen. Subsequently, some of them could lead to big troubles. We consider the problem could be resolved by automatic ticket allocation.

There are no guarantees that employees communicate effectively in a way they produce the desired result. In our opinion, modern information and communication technologies (ICT) are a reliable method for communication measurement, which the construction industry could benefit from. Moreover, ICT, no matter hardware and/or software-based, are able to create sound wave images. They could be useful in communication catching and its encryption. This traffic brings very important information and it is highly recommended to be saved and secured. It is advisable only artificial intelligence (AI) to read and access this information flow. Basing on it, AI can be taught to make qualitative and quantitative analyses. It can provide them via web services at any time when it is necessary. That way reduces risks of privacy violation because the human factor does not have access to sensitive information. The technology could also decrease some subjective issues and avoid any risks, caused by interpersonal conflicts. 
Komal Tomar (2014) uses Baron-Cohen's Mindreading System, which consists of four modular components. They are:

1. The Intentionality Detector (ID) interprets the self- propelled motion of stimuli in terms of primitive volitional mental states of goal or desire. It builds dyadic representations, which specify the relation (desire or goal) between an agent and an object (or another agent);

2. Eye-Direction Detector (EDD) detects the presence of eyelike stimuli in the visual field, computes whether the eyes are looking at it or at something else, and interprets gaze direction as a perceptual state. EDD codes dyadic representational states of the form [Agent-looking atme] and [Agent-looking at-not me]. The self is mapped to elements of the user's computing environment;

3. The Shared Attention Mechanism (SAM) is held to be necessary for the development and production of joint- attention behaviors. SAM links ID to EDD by importing volitional terms from dyadic representations, into the relation slot of triadic representations, such that a person's goal or desire can be read from their eye-direction. SAM is also responsible for triggering ToMM;

4. The theory of Mind Mechanism or (ToMM) is responsible for our everyday ability to make sense of behavior in terms of mental states and predicts an Agent's behavior on the basis of such states. It represents the full range of mental state concepts and integrates mental state knowledge into a coherent and usable "theory" for humans to employ (Tomar, 2014, p. 507). Tomar (2014, pp. 508) writes that the mind-reading computer gives voice and movement to the paralyzed. It can communicate with the patients in coma. It also can be used for police and military purpose. The mind-reading program translates brain activity into words (Tomar, 2014, p. 508). Mind reading allows us to make sense of other people's behavior, predict what they might do next, and how they might feel (Tomar, 2014, p. 507). We believe that this technology is also applicable to construction. Based on our viewpoint, we designed a mobile application that tracks the communication frequency between teams. The application is both web-based and mobile and it has five subsystems.

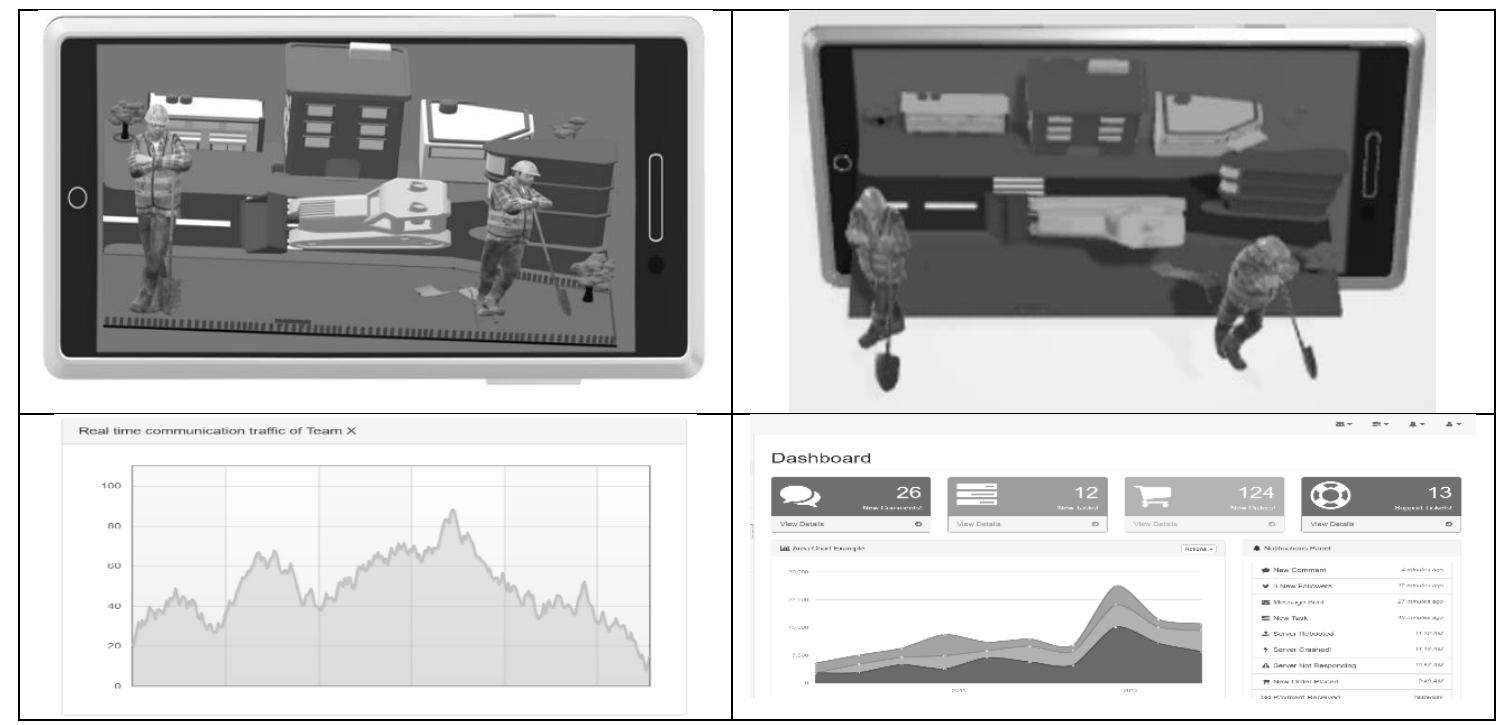

Source: An author's project, based on some ready-to-use Bootstrap templates.

Figure 1. Some Modules of The Communication-Based Auto-Control System, Including Dashboard, Real-Time Communication Traffic Generation, Monitoring Performance with 3D Tools

The first module allows sending and receiving audio, video and text messages and calls. The second one provides an embedded module for converting the send packages into traceable traffic or sound waves. That demonstrates the actual progress in real-time. Each time the status is updated, so 
some charts are dynamically moving permanently. Gantt chart with task dependencies has the potential to connect dependent tasks automatically. That way, team members know the status of the different phases and aspects of the project. Team scheduling and resource management are essential too. Presenting them graphically is an easier tool for real-time controlling availability, skillset, cost, and allocation of workforce and construction materials (see figure 1). Based on those options, workload monitoring helps manage and plan teams' activity.

Our mobile app provides tools for automatic reports (see fig. 1) and a subsystem evaluates their reliability. In case users give low ratings, the algorithm self-improves its punctuality.

Cloud-based construction software gives enough room for unlimited file storage for documents. There are many more documents in a construction project than in any other regular project. Therefore, an e-document management system eases document management and transmission. Those files could be attached to any individual or group communication and track all updates.

If a team has unopened tickets, applications of artificial intelligence try to analyze them. When AI identifies problems, it reports and reallocates them.

The application has a tool for measuring and comparing communication between teams (see figure 2). Based on a resultative report, suggestions on project quality level can be made. Identification of problematic phases, where communication is low, can be useful. For that reason, our app saves all history. That gives the chance all information to be kept and to return to vulnerable phases when necessary. The mobile tool can also advise on gaps filling and lapses elimination. It has subsystems for self-evaluation and feedback because we consider all auto-control systems should support self-evaluation and users should be able to give feedback if the self-control and self-reporting tools work properly.

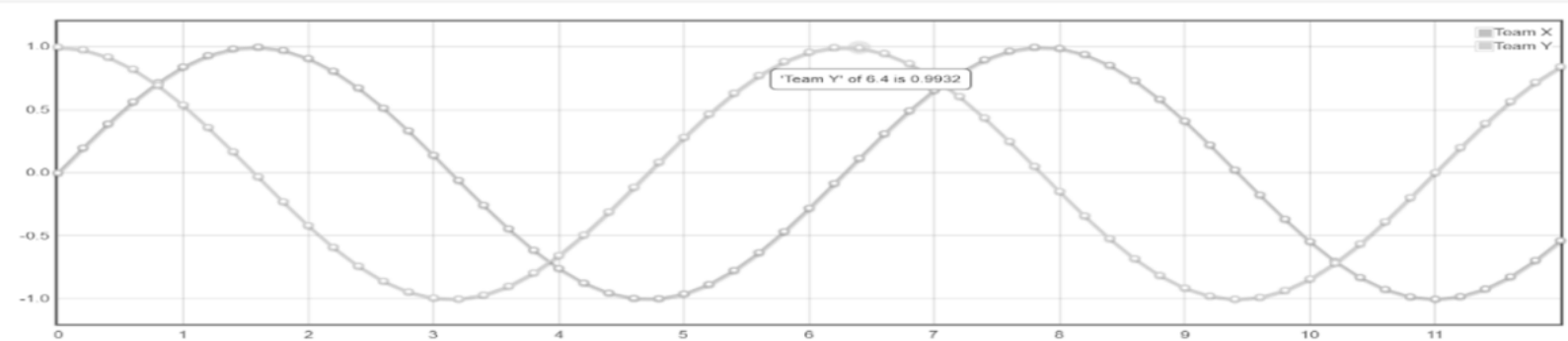

Figure 2. Dynamic Chart for Measuring and Comparing The Communication Activity Between The Teams by Dates and Hours

\section{Conclusion}

Phases in construction can vary, depending on the project size. They rely on good teamwork, effective communication, high-quality materials, reliable vendors, human experts, and qualified controlling tools. There are many rules, documentation, both physical and virtual tests for quality control and examination, but neither one of them could meet all requirements in construction because some projects are unique and they need an individual approach. Audio, video, photo and text messages are a source of invaluable knowledge. The modern information and communication technologies can transform them in any form like a digit, sound wave, radio signal, traffic, etc. That allows them to be used for different computer analyses. The last one has the potential to complement the controlling process. On the one hand, it appears to be a complementary tool for controlling by people. On the other hand, it gives all chances for fault-tolerance control by artificial intelligence. The construction industry currently adopts ICT but there is a need for automatic communication measurement. It gives much information about the project and team performance and can become indisputable proof for automatic quality assurance. That gives us reason to believe that the mobile application will contribute to improving communication in each phase of the construction project. 


\section{References}

1. Akinci, B. et al., (2006) A formalism for utilization of sensor systems and integrated project models for active construction quality control. Automation in Construction, Vol. 15, Issue 2, pp. 124-138.

2. Bureau of Labor Statistics of the United States, (2018) Labor Force Statistics from the Current Population. Employed persons by detailed industry, sex, race, and Hispanic or Latino ethnicity. [Online] Available at: https://www.bls.gov/cps/cpsaat18.htm, [Accessed 1010 2019].

3. European Commission, (2019) Construction. [Online] Available at: https://ec.europa.eu/growth/sectors/construction_en, [Accessed 1310 2019].

4. Furst, P., (2012) Ineffective Construction Management Practices and Their Impact on Project Safety. [Online] Available at: https://www.irmi.com/articles/expert-commentary/ineffectiveconstruction-management-practices, [Accessed 1010 2019].

5. GetApp, (2019) Construction Management Software. [Online] Available at: https://www.getapp.com/construction-software/construction-management/?sort=reviews\&oses _slug\%5B\%5D=web-based\&tag_slug=quality-control, [Accessed 1010 2019].

6. Gilliland Construction Management, (2019) What is the Pre-Construction Phase?. [Online] Available at: https://gillilandcm.com/2019/04/08/what-is-the-pre-construction-phase/, [Accessed 1110 2019].

7. IADC, (2019) Design Phases of a Project. [Online] Available at: https://www2.iadcdredging.com/subject/concept-contract-completion/design-phases-project, [Accessed $15 \quad 10$ 2019].

8. Imbimbo, N., (2018) 60 Must-Know Construction Statistics for 2019. [Online], Available at: https://www.bigrentz.com/blog/construction-statistics, [Accessed 1010 2019].

9. IRIS Construction, (2019) The Phases of a Construction Project. [Online] Available at: https://irisconstruction.ca/blog/the-phases-of-a-construction-project/, [Accessed 1010 2019].

10. JBKnowledge, (2018) The 2018 ConTech Report, Bryan, Brazos: JBKnowledge.

11. Klinger, M. \& Susong, M., (2006) The Construction Project: Phases, People, Terms, Paperwork, Processes. Illinois: ABA Publishing.

12. Marsden, P., (2019) Digital Quality Management in Construction. 1st ed. Abingdon: Routledge.

13. Martinez, P., Ahmad, R. \& Al-Hussein, M., (2019) Automatic Selection Tool of Quality Control Specifications for Off-site Construction Manufacturing Products: A BIM-based Ontology Model Approach. Modular and Offsite Construction. pp. 141-148.

14. Nacheva, R. \& Sulova, S., (2018) Approach to exploring users' expectations of digital services' functionality. Ekonomiczne Problemy UsÏug, 2(131), pp. 137-144.

15. NBS, (2018) National BIM Report 2018, RIBA Enterprises Ltd.

16. Oberlender, G., (2001) Project Management for Engineers and Construction, Second Edition. In: M. Science/Engineering/Math, ed. Project Management for Engineers and Construction, Second Edition, McGraw-Hill Science.

17. Sitemate, (2019) Quality control procedures in construction. [Online] Available at: https://sitemate.com/resources/articles/quality/quality-control-procedures-construction/, Accessed 1010 2019].

18. Sulova, S., (2016) An Approach For Automatic Analysis Of Online Store Product And Services Reviews. Izvestiya. Journal of Varna University of Economics, 60(4), pp. 455-467.

19. Swamy, R., (2019) Quality Control. In: Quality Control Civil work: Civil engineering Guide India. Independently published, pp. 1-211.

20. Tomar, K., (2014) How Mindreading Computer Work And How It Is Useful In Different Working Areas? International Journal of Computer Applications Technology and Research, 3(8), pp. 505509.

21. Xu, S. \& Luo, H., (2014) The Information-related Time Loss on Construction Sites: A Case Study on Two Sites. SAGE Journals, 01 01, 11(8), pp. 1-12. 